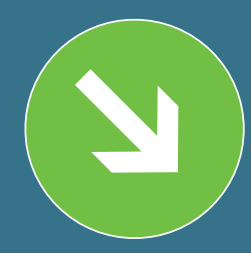

\title{
НА ПУТИ К «ИНДУСТРИИ 4.0»: ПРОФЕССИОНАЛЬНЫЙ ДИАЛОГ ЛИДЕРОВ ОТРАСЛИ
}

\author{
Юрий СУХАНОВ
}

Согласно последнему исследованию аналитической компании BusinesStat, продажи металлообрабатывающих станков с 2014 по 2018 год выросли более чем на $13 \%$. Эксперты отмечают, что подобная динамика связана с появлением более производительного автоматизированного оборудования, минимизирующего влияние человеческого фактора на процесс металлообработки. Увеличение спроса также связывают с внедрением универсальных обрабатывающих центров с ЧПУ, в которых обработка осуществляется в одном технологическом цикле.

Сегодня уже недостаточно просто создавать высококачественный инструмент, важна его интеграция в сложную автоматизированную производственную систему. Именно поэтому произво- дители режущего инструмента объединяют усилия с САМ-разработчиками. Подобное сотрудничество открывает быстрый и короткий путь к повышению эффективности производства в интересах клиентов и заказчиков.

Так, компания Sandvik Coromant привлекла своего давнего партнера - компанию CNC Software, разработчика популярной САM-системы Mastercam, - для проектирования технологии, которая использовала бы нелинейные свойства динамических стратегий обработки для точения деталей из труднообрабатываемых материалов. Перед Sandvik Coromant стояла задача повысить качество точения компонентов из нержавеющих сталей и жаропрочных сплавов с помощью инструмента с керамическими пластинками. Ранее отра-

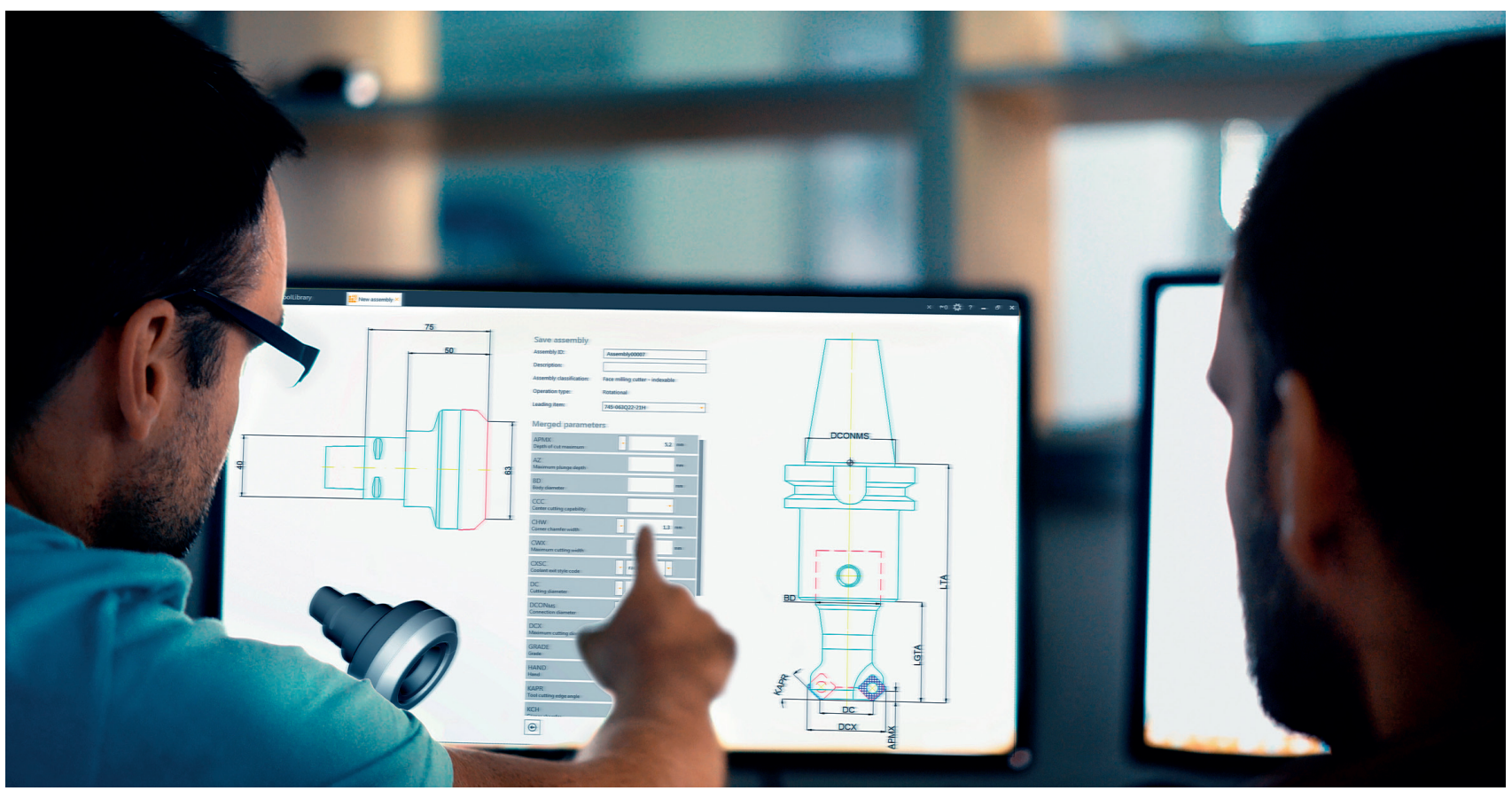

Puc. 1. Работа с CoroPlus Toollibrary 


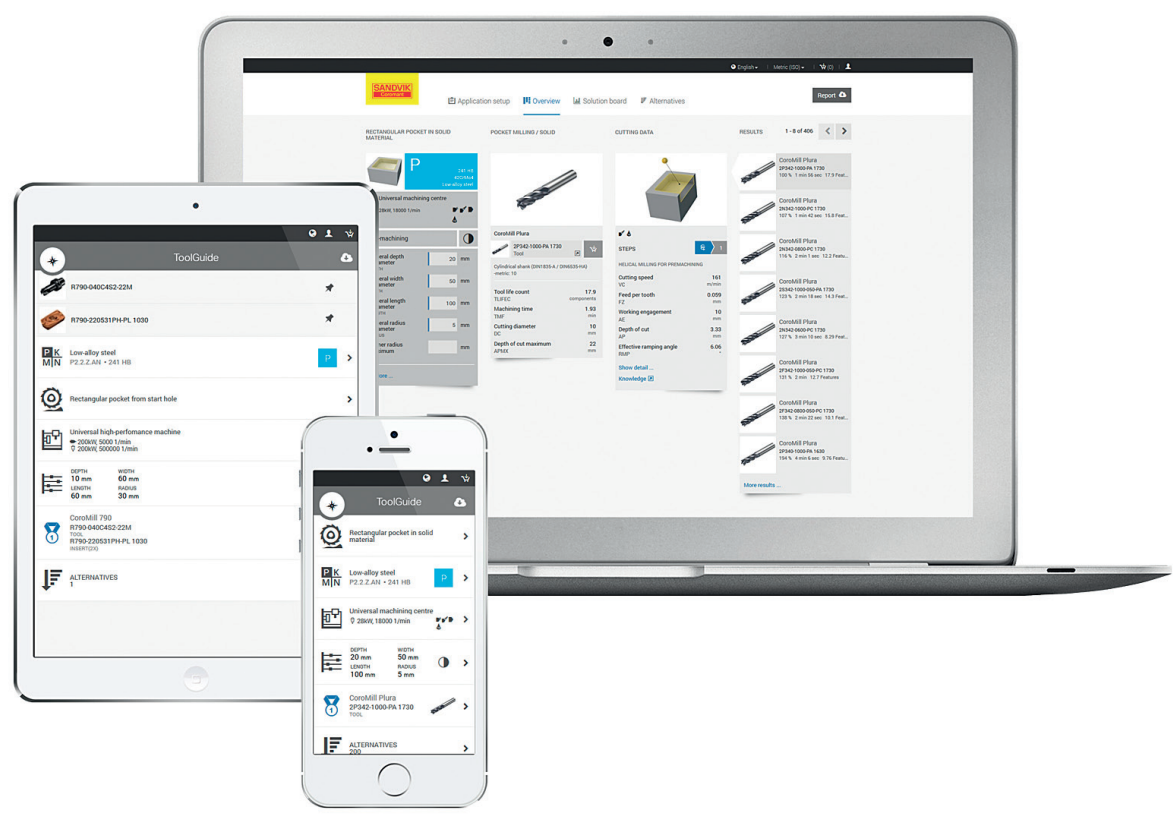

Puc. 2. Установка на различных устройствах приложения с информацией о режущих инструментах Sandvik Coromant

ботка станком традиционных линейных токарных траекторий при точении полным радиусом пластины нередко сопровождалась возникновением вибраций, что выводило инструмент из строя, а также ухудшало качество поверхности и приводило к проблемам со стружкой. В тесном сотрудничестве специалисты компаний смогли разработать оптимальные траектории с нелинейными перемещениями режущего инструмента, что позволило распределить износ равномерно по режущей кромке. Таким образом, были достигнуты значительные результаты в области снижения вибрации и лучшего распределения износа, что повысило производительность динамического точения. Благодаря новой технологии, предприятия, использующие Mastercam и режущий инструмент Sandvik Coromant, значительно сократили время обработки и увеличили срок службы инструмента более чем в четыре раза.

Кроме этого, передовые САМ-стратегии помогают достигать максимальной эффективности инновационных инструментальных решений.

Компания Sandvik Coromant обратилась к CNC Software, компании-разработчику Mastercam, чтобы реализовать новый метод PrimeTurningтм точение во всех направлениях. Без сотрудничества с САМ-партнером, способным разработать новый алгоритм создания необходимых траекторий токарной обработки, внедрение нового метода было бы невозможно. Для CNC Software задача заключалась в том, чтобы реализовать заданную спецификацию метода в Mastercam и провести собственные испытания. В результате, специалистами компании было разработано новое программное обеспечение, генерирующее оптимизированный код для станков с ЧПУ, которое позволило применить метод PrimeTurningтм, тем самым повысив коэффициент использования оборудования.

Кроме этого, компания CNC Software была одной из первых CAM-компаний, которая оказала поддержку проекту CoroPlus® Tool Library (ранее Adveon) от Sandvik Coromant (рис. 1). Это программное приложение предоставило удобный доступ к информации о режущих инструментах Sandvik Coromant пользователям Mastercam, что, в свою очередь, дало возможность легко создавать точную сборку инструмента для импорта в САMсистему (рис. 2). В 2018 году Sandvik Coromant предоставила лицензии Mastercam своим техническим специалистам по всему миру, в том числе и в России. Новая САМ-платформа помогла реализовать необходимый функционал для решения задач.

Таким образом, неустанный поиск новых решений, непрерывное совершенствование как режущих инструментов, так и технологий построения эффективных траекторий, управляющих ими, в совокупности не только повышают эффективность предприятий, но и становятся катализатором для общего развития отрасли и роста объема продаж, a сотрудничество между Sandvik Coromant и CNC Software/Mastercam доказывает результативность постоянного диалога между компаниями.

СУХАНОВ Юрий Семёнович -

председатель правления Группы компаний COLLA 